\title{
Healthy lifestyles in Europe: prevention of obesity and type II diabetes by diet and physical activity
}

\author{
Arne Astrup* \\ Research Department of Human Nutrition, The Royal Veterinary and Agricultural University, Denmark.
}

\begin{abstract}
The prevalence of obesity is increasing rapidly in all age groups in most EU-countries and is one of the fastest growing epidemics, now affecting 10-40\% of the adult population. Obesity increases the risk of serious co-morbidities such as type 2 diabetes, cardiovascular disease, certain cancers and reduced life expectancy, and these complications may account for $5-10 \%$ of all health costs in EU countries. The risk of diabetes is particularly increased by obesity, and $80-95 \%$ of the increase in diabetes can be attributed to obesity and overweight with abdominal fat distribution. There is robust evidence from cross-sectional and longitudinal studies to support that an energy-dense, high fat diet and physical inactivity are independent risk factors for weight gain and obesity. Furthermore, interaction between dietary fat and physical fitness determine fat balance, so that the obesity promoting effect of a high fat diet is enhanced in susceptible subjects, particularly in sedentary individuals with a genetic predisposition to obesity.

Ad libitum consumption of diets low in fat and high in protein and complex carbohydrates, with a low glycaemic index, contributes to the prevention of weight gain in normal weight subjects. It also causes a spontaneous weight loss of $3-4 \mathrm{~kg}$ in overweight subjects, and has beneficial effects on risk factors for diabetes and CVD. To prevent obesity and diabetes there are grounds for recommending the combination of increasing daily physical activity level to a PAL-value of at least 1.8 and reducing dietary fat content to $20-25$ energy-\% in sedentary subjects, and to $25-$ $35 \%$ in more physically active individuals.
\end{abstract}

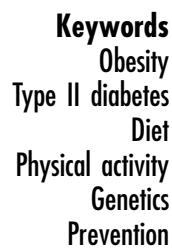

\section{The burden of obesity and diabetes}

The rapid increase in the global prevalence of obesity has been characterised as an epidemic by the $\mathrm{WHO}^{1}$. In most affluent populations the prevalence of obesity (BMI $>$ $\left.30 \mathrm{~kg} / \mathrm{m}^{2}\right)$ among adults is $10-40 \%$. Overweight $(25<$ BMI $<30 \mathrm{~kg} / \mathrm{m}^{2}$ ) affects an even larger proportion of the population than obesity. Overweight carries in itself an increased risk of the same complications as obesity and the risk is particularly high with abdominal obesity. The major complications are non-insulin-dependent diabetes (NIDDM or type 2 diabetes), ischaemic heart disease, hypertension, stroke, certain cancers and physical disability, which together may account for $5-10 \%$ of all health costs (Table 1).

Diabetes is the most important medical consequence of obesity because it is common, has serious complications, is difficult to treat, reduces life expectancy by $8-10$ years and is expensive to manage. Type 2 diabetes is rapidly becoming one of the major non-communicable diseases in the EU. It accounts for $80-90 \%$ of the existing 110 million diabetics worldwide, a number which is expected to reach 180 million by the year $2010^{2}$. Overweight with abdominal fat distribution and obesity account for perhaps $80-95 \%$ of cases of type 2 diabetes and remain a major obstacle to the successful long-term management of the disease ${ }^{3}$. Women with a BMI of 23-24 are at 4-fold higher risk of type 2 diabetes than women with BMI $<22$. Women with a BMI of 24-25 have a 5-fold increased risk, and those with BMI $>35$ have a 93-fold increased risk, of type 2 diabetes $^{4}$ (Fig. 1). Recent weight gain adds further to the risk of developing diabetes ${ }^{4}$. If body fat and fat distribution are taken into account an even larger proportion of diabetes cases can be explained by excess fat deposition.

Although diabetes is not directly the cause of most of the excess mortality among obese subjects, the metabolic abnormalities underlying type 2 diabetes are clearly the result of obesity (Fig. 2), which in itself predisposes to hypertension and cardiovascular disease. Individuals with type 2 diabetes are at a high risk of developing a range of debilitating complications that can lead to disability and premature death. Cardiovascular disease is a particular problem for type 2 diabetics and $75 \%$ of deaths among 
Table 1 Relative risk of health conditions caused by obesity ${ }^{1}$

\begin{tabular}{|c|c|c|}
\hline $\begin{array}{l}\text { Greatly increased } \\
(\text { relative risk } \gg 3)\end{array}$ & $\begin{array}{l}\text { Moderately increased } \\
\text { (relative risk ca. } 2-3 \text { ) }\end{array}$ & $\begin{array}{l}\text { Slightly increased } \\
\text { (relative risk ca 1-2) }\end{array}$ \\
\hline $\begin{array}{l}\text { Diabetes } \\
\text { Gall bladder disease } \\
\text { Hypertension } \\
\text { Dyslipidaemia } \\
\text { Insulin resistance } \\
\text { Breathlessness } \\
\text { Sleep apnoea }\end{array}$ & $\begin{array}{l}\text { Coronary heart disease } \\
\text { Osteoarthritis (knees) } \\
\text { Hyperuricaemia and gout } \\
\text { Asthma }\end{array}$ & $\begin{array}{l}\text { Cancer (breast cancer in postmenopausal women, } \\
\text { endometial cancer, colon cancer) } \\
\text { Reproductive hormone abnormalities } \\
\text { Polycystic ovary syndrome } \\
\text { Impaired fertility } \\
\text { Low back pain } \\
\text { Increased anaesthetic risk } \\
\text { Foetal defects arising from maternal obesity }\end{array}$ \\
\hline
\end{tabular}

individuals with type 2 diabetes are due to coronary heart disease. Such individuals experience a more than doubled risk of heart attack or stroke. Individuals with diabetes are at 17 times greater risk of peripheral vascular disease leading to amputation than non-diabetics ${ }^{2}$. Nephropathy can be seen in $8 \%$ of patients at the time of diagnosis and occurs in $40 \%$ of individuals who have had diabetes for 20 years. At diagnosis $25 \%$ of individuals with type 2 diabetes have already undergone changes to the retina, and about $2 \%$ of the diabetic population is blind.

Some of these defects are reversible with weight loss, with a corresponding improvement in mortality. In a Swedish weight loss intervention study on obesity the 2year incidence of diabetes was $6.3 \%$ in the control group and only $0.2 \%$ in the weight loss group ${ }^{5}$. This intervention study shows that $>95 \%$ of new cases of type 2 diabetes among obese individuals can be prevented by a sustained weight loss 5 . Most of the benefit was maintained at 10 years when the incidence of diabetes was still 5-fold lower than in controls, which corresponds to an $80 \%$ protection against developing diabetes ${ }^{6}$. In overweight diabetics the excess mortality is reversed by a $15-20 \%$ weight loss in the first year after diagnosis ${ }^{7}$. A deliberate weight loss of $0.5-9.0 \mathrm{~kg}$ is associated with a 30-40\% reduction in diabetes related mortality ${ }^{8}$ (Fig. 3).

\section{Secular trends in obesity and diabetes in EU}

The prevalence of diabetes and the number of people affected by the disease in the EU is increasing rapidly. Causes are changes in ethnicity, the size of the population, sex distribution, age structure, degree of urbanisation, and the increasing prevalence of overweight and obesity. Even without taking the expected impact of the obesity epidemic into consideration the increase in the prevalence of diabetes and the number of individuals affected in the first quarter of the 21st century is predicted to increase epidemically ${ }^{9}$. In the developed countries there will be a $27 \%$ increase in the prevalence of adult diabetes, and a $42 \%$ increase in the number of people with diabetes, from 1995 to $2025^{\circ}$. For the EU the expected increases in the prevalence of diabetes and the number of affected individuals are shown in Table 2. These data are from 1995 and newer surveys suggest that the prevalence of diabetes already exceeds the prediction in certain countries. For example, in the U.K. a survey

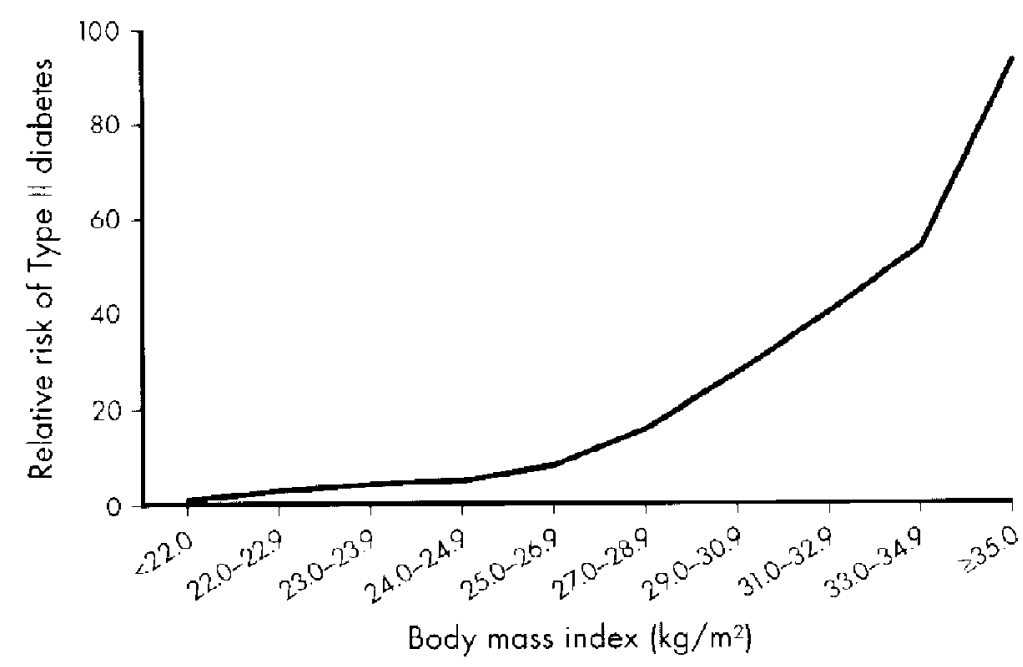

Fig. 1 Relative risk of type 2 diabetes increases with greater body mass index (BMI) in women. A BMI $>35 \mathrm{~kg} / \mathrm{m}^{2}$ increases the risk of diabetes by 93 -fold. The relation clearly demonstrates that type 2 diabetes essentially does not occur in lean women with a $\mathrm{BMI}<22 \mathrm{~kg} / \mathrm{m}^{24}$ 


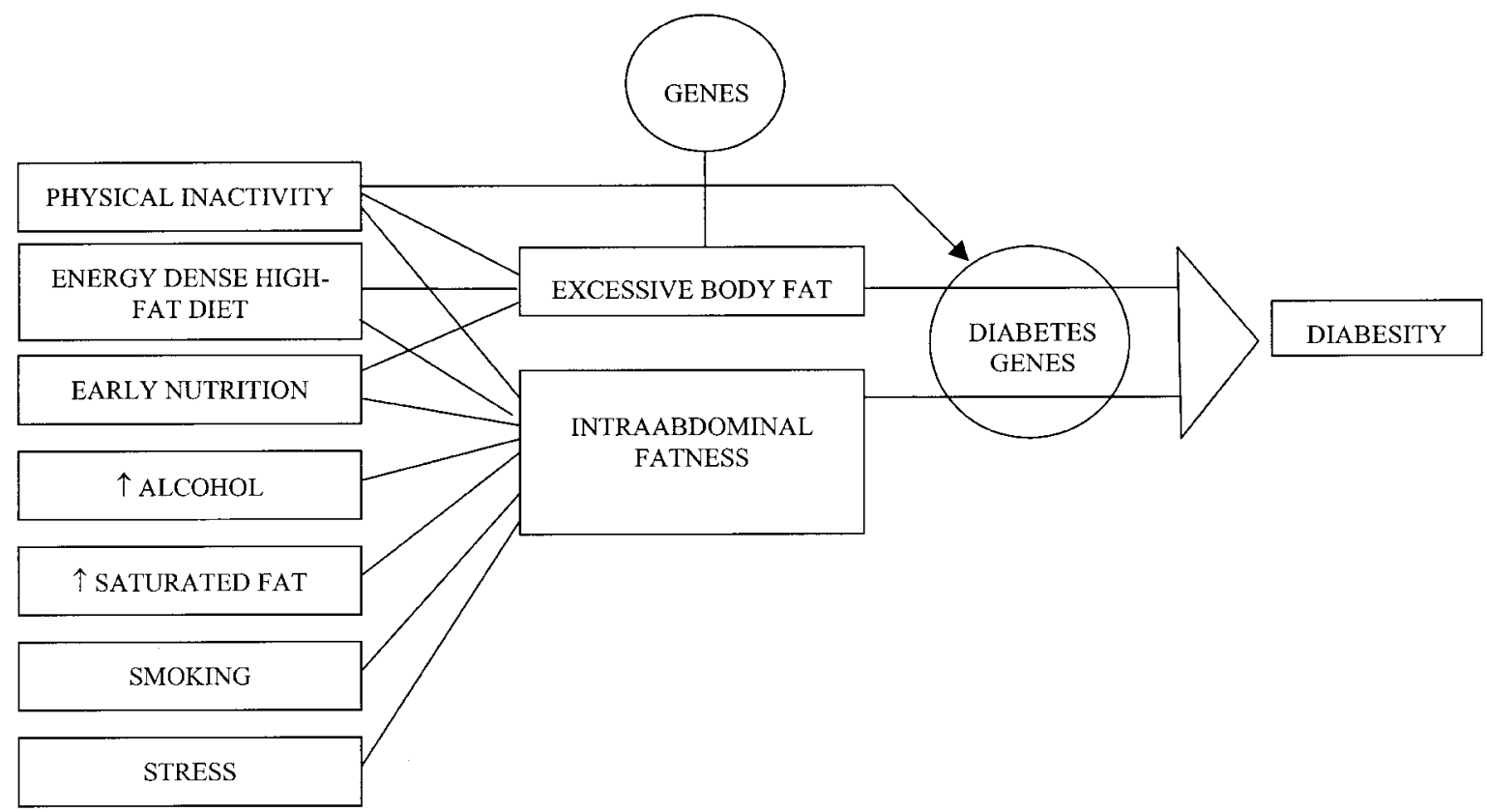

Fig. 2 A model to explain the contribution of different environmental factors to the development of type 2 diabetes. Most factors seem to exert their effect though an adverse effect of the enlarged body fat stores and of intraabdominal fat depositions in individuals with susceptibility genes, which together with physical inactivity is markedly responsible for the increased predisposition to diabetes (Modified from Astrup \& Finer ${ }^{3}$ )

from Manchester indicates that $10 \%$ of the adult population is undergoing treatment for diabetes and that an even larger proportion of the population would be classified as having type 2 diabetes if the newly revised WHO criteria are applied (Kennedy Cruickshank, personal communication).

\section{Pathogenic mechanisms}

It is generally accepted that obesity develops on the background of a genetic predisposition and increased susceptibility may be developed by interaction with other factors, e.g. fetal programming. Weight gain and obesity develops in susceptible individuals when they are exposed to a lifestyle characterised by physical inactivity and an abundant availability of energy dense, high fat, palatable foods. The importance of these factors will be reviewed.

\section{The role of diet composition and energy density}

The abundant food energy supply in the majority of populations has removed limited energy availability as a restricting factor for the development of obesity. The

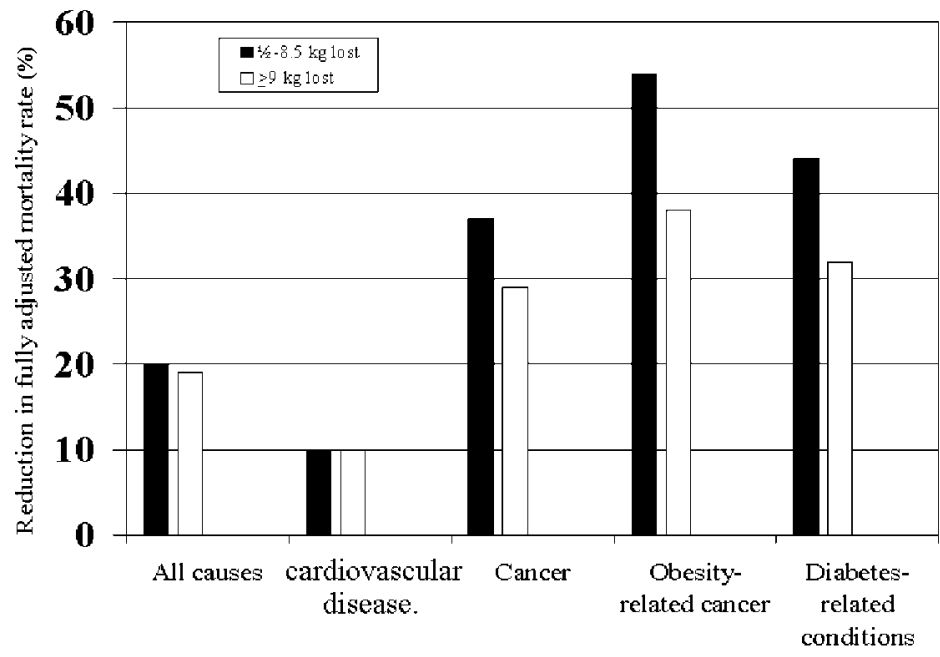

Fig. 3 Intentional weight loss results in significantly reduced mortality rates for women with obesity related health problems. Mortality in obese type 2 diabetics was reduced by $44 \%$ with an intentional weight loss of $1-19 \mathrm{lb}(0.5-9 \mathrm{~kg})$ (Modified from Williamson et al. $\left.{ }^{8}\right)$ 
Table 2 Estimated prevalence of population type 2 diabetes, numerical estimates, and projections in countries in the European Union from 1995 to $2025^{9}$

\begin{tabular}{|c|c|c|}
\hline Country and year & Prevalence (\%) & $\begin{array}{c}\text { Number of people } \\
(000)\end{array}$ \\
\hline \multicolumn{3}{|l|}{ Austria } \\
\hline 1995 & 2.0 & 123 \\
\hline 2000 & 2.1 & 130 \\
\hline 2025 & 2.7 & 178 \\
\hline \multicolumn{3}{|l|}{ Belgium } \\
\hline 1995 & 2.1 & 164 \\
\hline 2000 & 2.2 & 171 \\
\hline 2025 & 2.7 & 221 \\
\hline \multicolumn{3}{|l|}{ Denmark } \\
\hline 1995 & 8.3 & 329 \\
\hline 2000 & 8.4 & 335 \\
\hline 2025 & 10.8 & 428 \\
\hline \multicolumn{3}{|l|}{ France } \\
\hline 1995 & 2.1 & 881 \\
\hline 2000 & 2.1 & 935 \\
\hline 2025 & 2.6 & 1,234 \\
\hline \multicolumn{3}{|l|}{ Germany } \\
\hline 1995 & 2.1 & 1,359 \\
\hline 2000 & 2.2 & 1,434 \\
\hline 2025 & 2.8 & 1,770 \\
\hline \multicolumn{3}{|l|}{ Greece } \\
\hline 1995 & 7.6 & 607 \\
\hline 2000 & 7.8 & 650 \\
\hline 2025 & 9.6 & 772 \\
\hline \multicolumn{3}{|l|}{ Iceland } \\
\hline 1995 & 7.0 & 13 \\
\hline 2000 & 7.8 & 14 \\
\hline 2025 & 9.3 & 23 \\
\hline \multicolumn{3}{|l|}{ Ireland } \\
\hline 1995 & 1.8 & 43 \\
\hline 2000 & 1.8 & 46 \\
\hline 2025 & 2.3 & 66 \\
\hline \multicolumn{3}{|l|}{ Italy } \\
\hline 1995 & 7.5 & 3,369 \\
\hline 2000 & 7.8 & 3,592 \\
\hline 2025 & 10.0 & 4,365 \\
\hline \multicolumn{3}{|l|}{ Luxembourg } \\
\hline 1995 & 2.0 & 6.2 \\
\hline 2000 & 2.1 & 6.8 \\
\hline 2025 & 2.7 & 9.3 \\
\hline \multicolumn{3}{|l|}{ Netherlands } \\
\hline 1995 & 1.9 & 222 \\
\hline 2000 & 2.0 & 242 \\
\hline 2025 & 2.7 & 354 \\
\hline \multicolumn{3}{|l|}{ Norway } \\
\hline 1995 & 8.6 & 276 \\
\hline 2000 & 8.6 & 280 \\
\hline 2025 & 10.2 & 363 \\
\hline \multicolumn{3}{|l|}{ Portugal } \\
\hline 1995 & 7.1 & 513 \\
\hline 2000 & 7.3 & 538 \\
\hline 2025 & 8.8 & 674 \\
\hline \multicolumn{3}{|l|}{ Spain } \\
\hline 1995 & 7.2 & 2,156 \\
\hline 2000 & 7.3 & 2,303 \\
\hline 2025 & 9.5 & 2,952 \\
\hline \multicolumn{3}{|l|}{ Sweden } \\
\hline 1995 & 9.3 & 614 \\
\hline 2000 & 9.4 & 631 \\
\hline 2025 & 11.2 & 827 \\
\hline UK & & \\
\hline 1995 & 2.1 & 912 \\
\hline 2000 & 2.1 & 934 \\
\hline 2025 & 2.5 & 1,186 \\
\hline
\end{tabular}

proliferation of cheap, highly palatable, high fat, instant, fast and pre-packaged foods is assumed to contribute to overconsumption and to divest consumers of control over the preparation of their own foods.

\section{Regulation of the macronutrient balances}

The traditional concept of the energy balance equation, which describes weight gain as an excessive positive energy imbalance, can usefully be replaced by a series of macronutrient balance equations in which gains in body fat stores are viewed specifically as an imbalance of fat. The background for this replacement is that Joules are not equal in their metabolic effects, that interconversion between the 4 macronutrients is negligible, and that an oxidative hierarchy operates in inverse proportion to the size of available stores for each macronutrient. However, an excessive carbohydrate ingestion can lead to increased fat deposition by suppressing lipolysis and fat oxidation. Amino acid, glucose and alcohol oxidations adjust readily to protein, carbohydrate, and alcohol intakes. Seen over a period of a few days, regulation appears to be geared primarily to the suppression of hunger through gastrointestinal signals, to the maintenance of appropriate glycogen reserves and, to a lesser extent, to the maintenance of body fat stores.

Alcohol is most readily oxidised because it cannot be stored. Oxidation of carbohydrate and protein are also under tight auto-regulatory feedback control: oxidation increases in direct response to intake. In contrast, there is virtually no acute feedback between fat intake and fat oxidation. Fat oxidation is primarily a function of the gap between total energy expenditure and the amount of alcohol, protein and carbohydrate energy consumed, resulting in a much less accurately maintained fat balance. Though regulatory responses serving to achieve fat balance exist, their effectiveness in inhibiting the expansion of the fat mass seems to be limited. Leptin, a hormone secreted from adipose tissue at an increased rate when the fat mass is expanded, inhibits food intake and increases sympathetic nervous system activity through a central action. However, the 10-fold higher circulating leptin concentrations in obese than in lean subjects suggest that lipostatic mechanisms are insufficient to restrict energy intake in obese individuals. Long-term fat and energy balances tend to remain close to zero over prolonged periods once a weight maintenance plateau has been reached (i.e. less than $2-3 \%$ error relative to energy turnover considered over one year).

In conclusion, protein, carbohydrate and ethanol oxidation rates relate well to the respective intake of these nutrients. Dietary fat oxidation, however, relates poorly to daily variations in fat consumption. This is a probable explanation as to why obesity develops particularly among individuals with a genetically determined low fat oxidation capacity when the diet is high in fat and when physical activity is limited. 


\section{Role of diet composition in obesity and risk factors}

The establishment of a causal link between exposure to a diet component and weight gain and obesity should be based on all the available lines of evidence, i.e. feeding studies in experimental animals, observational crosssectional and longitudinal human studies, short-term experimental and mechanistic studies and intervention studies ${ }^{10}$. These lines of evidence will be reviewed briefly.

- Experimental studies on diet composition and energy intake. Considering the problem of weight gain and obesity, the issue is to determine the nature of the dietary components which facilitate consumption and lead to a positive energy balance. Dietary components can influence energy intake by acting during consumption and in the period following eating (post-ingestive period). Dietary protein exerts a potent effect on satiety and provides the strongest inhibition of energy intake. Delivered in iso-energetic amounts, high protein meals generate stronger satiety than high carbohydrate meals. An active area of interest involves comparisons of fat and carbohydrate. Subjects exposed to high fat foods for a period of weeks tend to overconsume energy. This effect depends largely on the high energy density of the high fat foods. The overeating effect has been referred to as passive overconsumption ${ }^{11,12}$. It should be noted that the stimulatory effect of fatty foods on energy intake is not only due to their high energy density but also to the probable facilitatory action of fat in the mouth. It has been known for many years that offering subjects high fat or high carbohydrate foods which have been manipulated to be equally energy dense eliminates the high fat overeating phenomenon in normal, non-genetically predisposed individuals.

The passive overconsumption effect of fat on energy intake is due to an action during consumption (it is an intra-meal effect). The large amounts of fat energy consumed do not appear to generate equivalent effects on post-ingestive satiety ${ }^{12}$. Therefore fat has a proportionally weaker effect on satiety relative to the amount of energy consumed. In studies where energetically equivalent preloads of fat and carbohydrate have been delivered it appears that fat does exert a weaker satiating effect (on a Joule for Joule basis) than the other macronutrients.

A large body of short-term studies on appetite and energy intake unequivocally show that fat is less satiating than carbohydrate and protein when compared Joule for Joule, and that high fat foods are more likely to induce passive overconsumption and weight gain than low fat foods $s^{13,14}$

- Observational studies linking diet composition with obesity. Numerous cross-sectional studies have clearly demonstrated positive associations between the proportion of total energy intake covered by fat and body fatness, and inverse associations between carbohydrate and body fatness ${ }^{13,14}$. In contrast, a number of longitudinal studies have been unable to establish any association between self-reported dietary fat and carbohydrate intakes and subsequent weight change. However, evidence based on observational studies looking for associations between habitual dietary macronutrient intakes and body fatness have a number of limitations due to their reliance on information about dietary intake given by the subjects under examination. Valid information on dietary fat intake is difficult to achieve in populations that are recommended to reduce fat intake, because they may either eat a more healthy diet during the dietary survey or they may under-report fat intake. Furthermore, because fat oxidation is not increased in response to acute increases in fat intake day-to-day fluctuations in dietary fat intake, which are not captured by reporting average fat intake, could lead to episodic bouts of fat storage. It is well established that overweight and obese subjects under-report their energy intake by 30-40\% (Fig. 4), and fat may be over-represented in this under-reporting ${ }^{15}$. Studies in health conscious populations show that high fat foods are under-reported whereas low fat foods are over-reported. It seems to be easier to demonstrate associations between dietary fat intake and subsequent weight changes in less health conscious populations such as in China, than in it is in the EU and the United States.

One may therefore question the validity of the dietary surveys reporting a decrease in fat consumption in the population. The surveys' estimates of dietary fat energy- $\%$ in U.S.A. show a decrease from $42 \%$ in 1965 to $37 \%$ in 1987 , whereas per capita values of fat intake and dietary fat energy- $\%$ based on food availability increased from 42 to 43 energy- $\%$ in the same period. Although the food disappearance data does not include some types of food losses and waste (e.g., trimming fat from meats), and commodities used in pet foods are not subtracted from the total amounts available in the food supply, the increasing lack of agreement is strongly suggestive of a substantial underreporting of dietary fat in the surveys. This is not surprising as one would expect subjects to report more healthy eating habits when asked to give information to nutrition experts. Moreover, the well described under-reporting of energy and fat consumption among obese subjects may have extra significance in surveys conducted in a population where the majority are either overweight or obese. Recent statistics actually demonstrate that fat consumption in the USA has not declined ${ }^{16}$.

In conclusion, cross-sectional studies quite consistently support that a high fat, low carbohydrate diet contributes to the maintenance of the obese condition. However the consistent outcome should not be given major weight in the assessment of the dietary fat and body fat relationship because of the methodological limitations in obtaining valid information about dietary macronutrient intakes in diet conscious and overweight populations. 


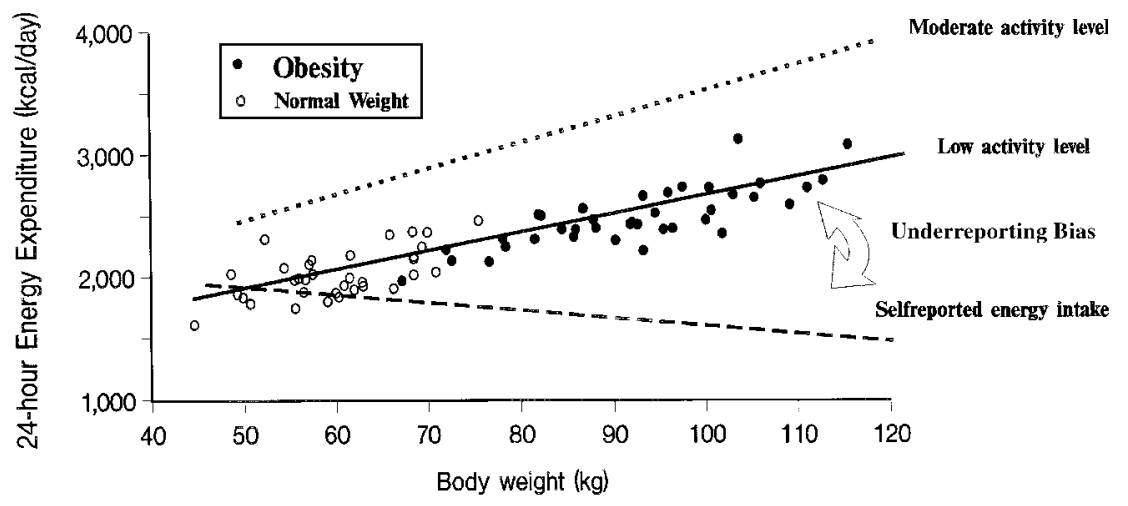

Fig. 4 Energy expenditure (energy requirements) of normal weight, and obese subjects. Relationships between body weight and energy requirements assessed by measurement of energy expenditure or by apparent energy intake during weight stability. The growing underreporting with increasing body fatness makes the self-reported energy intake invalid for estimation of energy requirements in obese individuals ${ }^{50}$

Intervention studies. Randomised, controlled, ad libitum, low fat, high carbohydrate diet intervention studies, with control groups maintaining their usual diet or consuming a medium to high fat diet, show mean weight losses in the intervention groups over a period of 3-6 months ranging between 0 and $10 \mathrm{~kg}$. This large variability and inconsistent outcome has created doubt about the effectiveness of a low fat diet in the prevention and treatment of overweight and obesity, and questioned the role of dietary fat in body fatness. Willett et al. have stated that 'Diets high in fat do not appear to be the primary cause of the prevalence of excess body fat in our society, and reductions in [dietary] fat will not be the solution' and 'in the longer term, fat consumption within the range of $18-40 \%$ appears to have little if any effect on body fatness ${ }^{17}$. One must admit that the weight loss achieved by a low-fat diet in some of the randomised clinical trials is so modest that it is difficult to imagine how a severely obese subject can benefit from a reduction in dietary fat. However, the suggestion that saturated fat should be replaced by monounsaturated fat rather than by carbohydrate may pose the risk that the current fat consumption, which already exceeds the recommended level, may be further increased.

Trials assessing the effect of ad libitum low fat diets on body weight may suffer from uncertainties about adherence to the diet composition, but the data may be improved by taking factors such as pre-treatment body weight, reduction in dietary fat and compliance into consideration. A recent systematic review concluded that dietary fat does play an important role in human obesity. Based on 28 intervention trials Bray and Popkin found that a reduction of $10 \%$ in the proportion of energy from fat was associated with a reduction in weight of $16 \mathrm{~g} / \mathrm{d}$, which corresponds to a weight loss of $2.9 \mathrm{~kg}$ over 6 months ${ }^{13}$. Our recently conducted meta-analysis including data from 18 controlled, ad libitum, low fat, 2-12 months trials on weight change involved 1728 normal and overweight individuals of both gender ${ }^{14}$. The analysis showed that a reduction in dietary energy from fat over 2-12 months is associated with a spontaneous weight loss of $2.5 \mathrm{~kg}(95-\% \mathrm{CI}, 1.5-3.5 ; \mathrm{P}<0.0001)$ more in the intervention than in the control group (Fig. 5). The analysis indicated that only minor weight loss occurred in groups with body weights in the normal range (60$72 \mathrm{~kg}$ ), but this group did not experience the slight weight gain seen in the control groups consuming normal fat diets. Weight loss increased progressively with increasing initial body weight. If extrapolated to a body weight of $88 \mathrm{~kg}$ (corresponding to a BMI $\sim 30 \mathrm{~kg} / \mathrm{m} 2$ ), and assuming a 10\%-point fat reduction from a typical habitual reported dietary intake of 38\% energy from fat, the predicted weight loss would be $4.4 \mathrm{~kg}$ (95-\% CI, 2.0 to $6.8 \mathrm{~kg}$ ). Another meta-analysis used more liberal inclusion criteria and was based on 37 dietary intervention studies published from 1981 to $1997^{18}$. The weight loss in the intervention groups was $2.79 \mathrm{~kg}$ larger than in the control groups, and there was a highly significant relationship between reduction in dietary fat and weight loss, so that for every $1 \%$ decrease in energy from fat there was a $0.28 \mathrm{~kg}$ decrease in body weight over a couple of months.

These analyses show that a reduction in dietary fat without restriction of total energy intake causes weight loss in a dose-dependent fashion and may produce weight stability in normal weight subjects, and a modest but clinically relevant weight loss in overweight subjects. The dose-dependent relationship between the reduction in fat energy- $\%$ and weight change found in these metaanalyses is important because it shows that there is a progressive effect on body weight when dietary fat content is reduced down to $15-20 \%$ fat energy (Fig. 6). This is also reflected in the FAO recommendations ${ }^{19}$ : 'Depending on their activity level and dietary pattern adults should receive between $15 \%$ and $35 \%$ of their Joules from fat'. Although it may not be realistic to reduce 

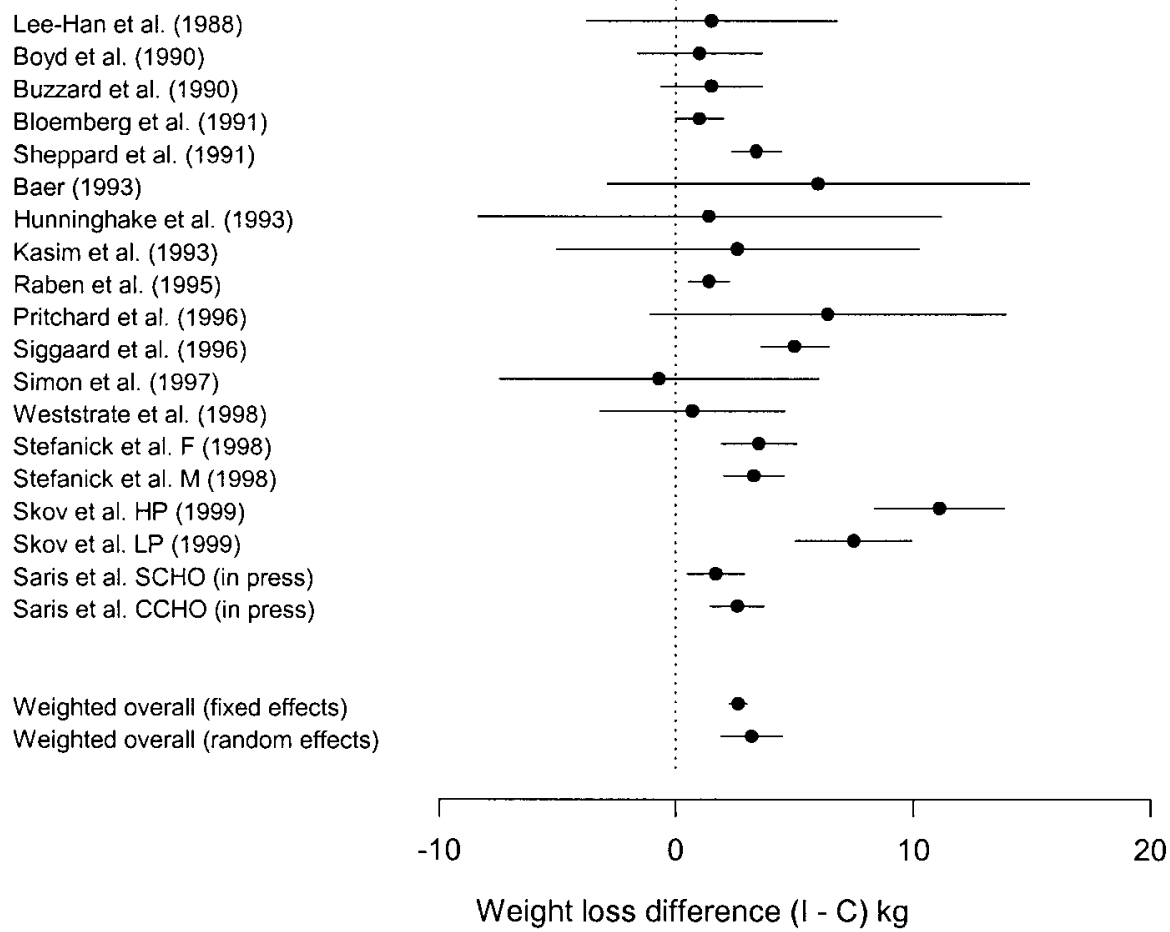

Fig. 5 Meta-analysis of weight loss produced by ad libitum low fat, complex carbohydrate rich diets from 16 studies lasting more than 2 months in normal weight and overweight subjects. Estimated differences in weight change (intervention minus control) (kg) with $95 \%$ confidence intervals. The estimates and $95 \%$ confidence intervals from the fixed effects and random effects meta-analysis are also shown ${ }^{14}$

dietary fat to less than $20 \%$ in EU populations, the $20 \%$ may be a requisite to prevent weight gain in sedentary individuals.

\section{- Importance of carbohydrate source and glycae-} mic index for obesity and risk factors. Carbohydrates contribute markedly to the satiating efficiency of foods and exert clear effects on satiety. This forms part of the 'glucostatic' mechanism of appetite control. A variety of carbohydrates, including glucose, fructose, sucrose and maltodextrins, exert fairly similar effects on satiety - when given in a pre-load they suppress later intake by an amount roughly equivalent to their energetic value. The time course of the suppressive action may vary according to the rate at which the high carbohydrate loads are metabolised, as demonstrated by the amylose content of starch. There is also some evidence that the degree of satiety is related to the glycaemic index of the carbohydrate in the food ${ }^{20}$. Resistant starch (dietary fibre) may prolong satiety by modulating the time course of the preand post-absorptive satiety signals. Fibre can also limit intake by lowering the energy density of the food, thus allowing time for satiation (and early satiety signals) to occur before large amounts of energy have been consumed.

The relative contributions of the carbohydrate sources in the diet have therefore potential implications for body weight regulation and obesity. The intake of alcohol and protein has remained relatively constant in most EU countries over the last 50 years and together these nutrients represent less than $20 \%$ of the total energy intake. The main dietary change has been the increase in fat intake at the expense of carbohydrates. The inverse relationship between dietary fat and carbohydrate has been demonstrated in numerous cross-sectional studies in countries with very different socio-economic status. It is particularly the simple sugars, rather than the complex carbohydrates, which tend to counterbalance the fat energy of the diet. This phenomenon has been dubbed 'fat-sugar see-saw'. Cross-sectional observational studies have quite consistently shown a negative association between body weight and the proportion of dietary carbohydrate, in particular simple sugars. One of the largest data sets is derived from the Scottish part of the Monica Survey and clearly shows an inverse relationship between sugar intake and obesity ${ }^{21}$. When divided into quintiles according to the fat:sugar ratio, there was a $2-3$ fold higher prevalence of obesity in the highest versus the lowest quintile. One of the shortcomings of crosssectional surveys is the possibility that the dietary pattern may represent a post-hoc event, i.e. that obese individuals have adopted a particular diet composition consequent to their obesity. For example, if obese subjects in an effort to reduce their energy intake have replaced sugars with artificial sweeteners their sugar intake will be low. Experimental studies and short-term intervention studies 
(a)

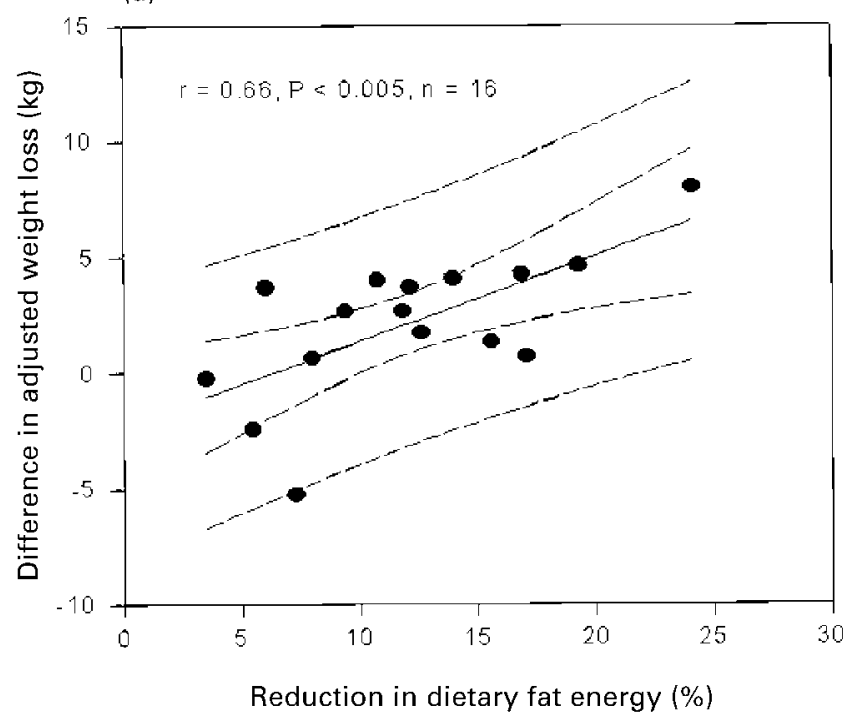

(b)

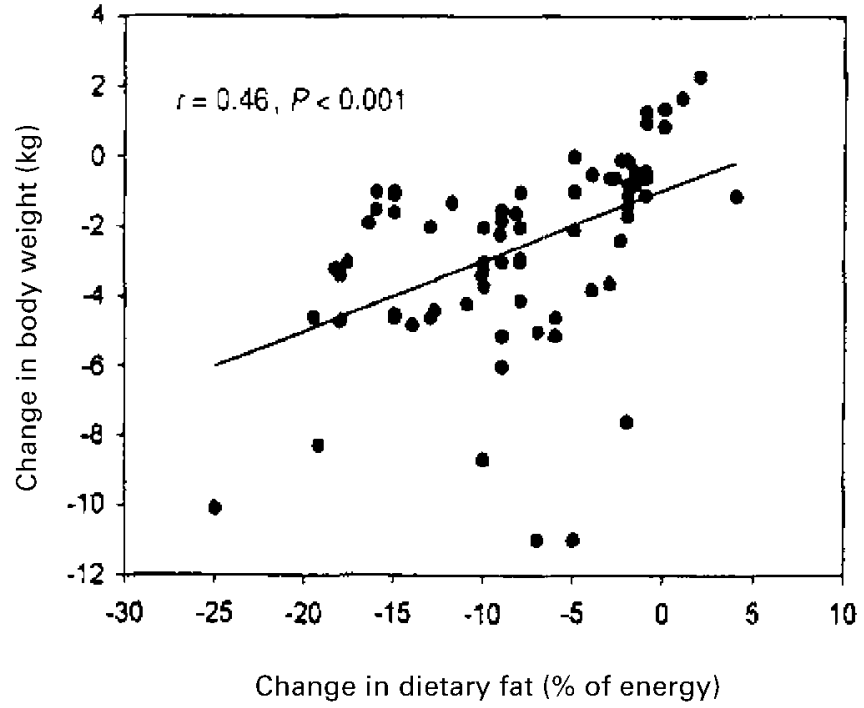

Fig. 6 Meta-analyses of relationship between reduction in dietary fat content and spontaneous reduction in body weight. Each dot represents a study. Upper panel ${ }^{14}$. Lower panel ${ }^{18}$

do not provide a firm conclusion as some studies suggest that low fat, high sugar diets may increase energy intake above that of a similar low fat diet with a high complex carbohydrate content ${ }^{22}$. The only available long-term study is the European multicenter trial CARMEN ${ }^{23}$. In that study 398 overweight and obese adults with a BMI between 26 and 35 were randomised to a dietary intervention of either a low fat, high simple carbohydrate diet, a low fat, high complex carbohydrate diet, or to continuation of the control diet. The diets were supplied by a validated laboratory shop system. A diet low in fat and with an increased level of complex carbohydrates lowered body fat mass by $2.4 \mathrm{~kg}$ more than the control diet. To a lesser extent it also reduced fat mass compared to the control diet $(1.9 \mathrm{~kg})$. Though the difference in weight loss between complex and simple carbohydrate groups was not statistically significant, it is possible that the low fat, simple carbohydrate diet is slightly less effective in inducing weight loss. It should be noted that there was no difference in energy density between the two low fat diets in the CARMEN study. Given the important role of energy density in passive overconsumption the introduction of low fat, low moisture content foods, such as cakes and biscuits in which fat is substituted by simple sugars but energy density is unchanged, may impair the expected decrease in energy intake and hence play a role in maintaining excess body weight in some subjects. 
- Diet composition and prevention of diabetes. Prevention of weight gain and obesity are key features in the prevention of diabetes. However, apart from an effect on body weight, diet composition also has effects on risk factors associated with diabetes and its major complications. There is even some epidemiological evidence to support that the consumption of high-glycaemic index diets is an independent risk factor of developing diabetes $^{24,25}$. Some evidence is available for a differential effect of carbohydrate sources on insulin resistance, on blood lipids and on other cardiovascular risk factors. It is often argued that a reduction in total fat intake, accompanied by a rise in carbohydrate intake, leads to a rise in plasma triglycerides and a fall in plasma HDLcholesterol, which would be expected to increase the risk of CHD. Furthermore it has been suggested that monounsaturated fat (MUFA) has a more beneficial effect on risk factors of CHD than carbohydrate. This is true in studies where carbohydrate has been compared with MUFA under strictly isoenergetic conditions and no weight loss was allowed to occur on the low fat, complex carbohydrate diet. But in studies allowing ad libitum intake the changes in blood lipids are dominated by the slight weight loss induced by the low fat diet. This was illustrated by Schaefer et al. in a study on hyperlipidemic individuals where the dietary fat content was first changed from 35 to 15 energy- $\%$ under isoenergetic conditions so that body weight was kept constant ${ }^{26}$. After 6 weeks total cholesterol was reduced by $13 \%$ and LDLcholesterol by 17\%, but HDL-cholesterol decreased by $23 \%$ and plasma triglycerides increased by $47 \%{ }^{26}$. Subsequently the individuals continued for a further 10-12 weeks on an ad libitum diet of the same composition. Now the diet caused a mean weight loss of $3.6 \mathrm{~kg}$, a further reduction in LDL-cholesterol, and the normalisation of plasma triglycerides and the ratio of HDLcholesterol/total-cholesterol. This has been confirmed in a systematic review and meta-analysis evaluating the effects of the American National Cholesterol Education Program's dietary interventions on major CVD risk factors $^{18}$ (evidence category A, see Table $3^{27}$ ).

However, the carbohydrate source and the glycaemic index may have importance for the effect on risk factors. Both observational and intervention studies show that a low glycaemic index diet exerts more beneficial effects than a high glycaemic index diet on LDL- and HDLcholesterol, insulin resistance, and plasminogen activator inhibitor-1 activity. The glycaemic index may have particular importance for determining HDL-cholesterol ${ }^{28}$. Consequently, the high carbohydrate content of low fat diets should stem mainly from the complex carbohydrates of different vegetables, fruits and whole grains, which are more satiating for fewer Joules than fatty foods, and are a good source of vitamins, minerals, trace elements and fibre. A high fibre content may further improve the satiating effect of the diet and a diet rich in soluble fibre, including oat bran, legumes, barley and most fruits and vegetables, has the most beneficial effect on blood lipids and blood pressure levels. The Nordic Dietary Recommendations recommend a fibre intake of 25 to 30 grams daily $^{29}$, and $18 \mathrm{~g} / \mathrm{d}$ (individual range $12-24 \mathrm{~g} / \mathrm{d}$ ) of nonstarch polysaccharides were proposed by the British Panel on Dietary Reference Values ${ }^{30}$.

In conclusion, there is little evidence to support that differences in carbohydrate source may be important for body weight regulation and propensity to obesity. While short-term studies suggest that foods with a low glycaemic index exert a stronger effect on satiety than those with a high index, long-term studies are lacking and the importance for body fatness is unknown. Changing from a high fat, low carbohydrate diet to a low fat, high carbohydrate diet with a low glycaemic index exerts beneficial effects on risk factors of cardiovascular disease and diabetes, while HDL-cholesterol may be lowered by high glycaemic index diets (evidence category B).

- Dietary recommendations for individuals with diabetes. According to the European Association for the Study of Diabetes (EASD) the dietary guidelines for the treatment of diabetes are very similar to recommendations for obese subjects and for the prevention of diabetes, except for a more liberal attitude to a higher total fat content providing $10-18$ of total energy- $\%$ derived from cis-monounsaturated fatty acids (MUFA) ${ }^{31}$. However, they admit that whether increased MUFA fat intake in diabetics inevitably leads to weight gain needs to be studied. Carbohydrate containing foods, which are rich in soluble fibre or have a low glycaemic index are especially recommended $^{31}$. Increased physical activity, even without a weight loss, contributes to the prevention of type 2 diabetes, and given the effects on body fat and other benefits more physical activity is an important part of the recommendations.

\section{- The role of protein for obesity and risk factors.} There is some concern that a high protein intake in infant formulas and during growth may increase the susceptibility to weight gain and obesity ${ }^{32}$. However, there is a large body of experimental data to suggest that protein possesses a higher satiating power per Joule in adults than carbohydrate and fat. The impact on obesity and risk factors of replacing carbohydrate with protein in ad libitum low fat diets has been addressed in only one randomised controlled trial. Two fat reduced diets (30\% of total energy), a high carbohydrate diet (protein 12\% of total energy) and a high-protein diet (protein 25\% of total energy) were compared in 65 obese individuals ${ }^{33}$. Weight loss after 6 months was $5.1 \mathrm{~kg}$ in the high carbohydrate and $8.9 \mathrm{~kg}$ in the high protein groups $(P<0.01)$, and more subjects lost $>10 \mathrm{~kg}$ in the high protein group (35\%) than in the high carbohydrate group (9\%). The protein rich diet had no adverse effect on blood lipids, 
Table 3 Evidence categories ${ }^{27}$

\begin{tabular}{|c|c|c|}
\hline Evidence Category & Sources of Evidence & Definition \\
\hline A & $\begin{array}{l}\text { Randomized controlled trials } \\
\text { (rich body of data) }\end{array}$ & $\begin{array}{l}\text { Evidence is from endpoints of well-designed RCTs } \\
\text { (or trials that depart only minimally from randomization) } \\
\text { that provide a consistent pattern of findings in the population } \\
\text { for which the recommendation is made. Category } \\
\text { A therefore requires substantial numbers of studies involving } \\
\text { substantial numbers of participants. }\end{array}$ \\
\hline $\mathrm{B}$ & $\begin{array}{l}\text { Randomized controlled trials } \\
\text { (limited body of data) }\end{array}$ & $\begin{array}{l}\text { Evidence is from endpoints of intervention studies that include } \\
\text { only a limited number of RCTs, post hoc or subgroup analysis } \\
\text { of RCTs, or meta-analysis of RCTs. In general, Category B } \\
\text { pertains when few randomized trials exist, they are small in size, } \\
\text { and the trial results are somewhat inconsistent, or the trials } \\
\text { were undertaken in a population that differs from the target } \\
\text { population of the recommendation. }\end{array}$ \\
\hline $\mathrm{C}$ & Nonrandomized trials Observational trials & $\begin{array}{l}\text { Evidence is from outcomes of uncontrolled or nonrandomized } \\
\text { trials or from observational studies. }\end{array}$ \\
\hline $\mathrm{D}$ & Panel consensus judgment & $\begin{array}{l}\text { Expert judgment is based on the panel's synthesis of evidence } \\
\text { from experimental research described in the literature and/or } \\
\text { derived from the consensus of panel members based on } \\
\text { clinical experience or knowledge that does not meet the above-listed } \\
\text { criteria. This category is used only in cases where the provision of } \\
\text { some guidance was deemed valuable but an adequately compelling } \\
\text { clinical literature addressing the subject of the recommendation was } \\
\text { deemed insufficient to justify placement in one of the other categories } \\
\text { (A through C) }\end{array}$ \\
\hline
\end{tabular}

renal function or bone mineral density. Replacement of some dietary carbohydrate by protein in ad libitum, low fat diets may improve weight loss. More freedom to choose between protein rich and complex carbohydrate rich foods may encourage obese subjects to choose more lean meat and dairy products and hence improve adherence to low fat diets in weight reduction programmes.

The consumption of meat and meat products has been linked epidemiologically to cancers at different sites. Ecological studies of diet and cancer have tended to show a correlation between meat intake, particularly red meat, and the risk of colo-rectal cancer, but more recent European case referent studies have failed to show any relationship ${ }^{34}$. The available evidence points to the intake of protective factors such as vegetables and whole-grain cereals being the main determinants of colo-rectal cancer risk, with meat intake being only coincidentally related ${ }^{34}$. The type, amount, processing, cooking and dose responses of meat or protein responsible for the increased risk of other cancers are uncertain, and the current recommendation of a $140 \mathrm{~g}$ limit is a pragmatic value, based on the distribution of meat intake in the UK population ${ }^{35}$.

In conclusion, the available evidence suggests that a diet with a protein content up to 25 energy- $\%$ may be beneficial for weight regulation in adults (evidence category B). Protein allowances in diets for weight reduction and for diabetics of up to 25 energy- $\%$ should await confirmation of the positive results by more randomized trials.
- Fat quality. Although similar amounts of different fats contain nearly the same amount of energy, differences may exist in their satiating effects, which may influence the total energy intake of ad libitum, low fat diets and weight maintenance diets. From a biochemical and physiological point of view fatty acids behave very differently, and monounsaturated fats (MUFA) seem to be more neutral than other fats in relation to insulin resistance, type 2 diabetes, CHD and cancer. However, animal studies suggest that MUFA increase body weight more than polyunsaturated fatty acids (PUFA) ${ }^{36}$. In a cross-sectional, observational study the highest positive correlation was found between the intake of MUFA and body fat mass, whereas no significant association was found between PUFA and body fat, and only a weak association to saturated fat was seen ${ }^{37}$. Two experimental appetite studies have concordantly shown that meals/ infusions with MUFA produce lower satiety and suppress energy intake for the remainder of the day less than PUFA $^{38}$. These preliminary reports suggest that a high MUFA content in the diet may promote passive over consumption and obesity. Until randomised clinical trials have been conducted some caution should be exercised in recommending replacement of PUFA with MUFA in diets for individuals susceptible to weight gain and obesity.

- Alcohol. The impact of alcohol intake on weight regulation is not well understood ${ }^{39}$. Observational epidemiological studies addressing the relationship between alcohol intake and obesity are probably more tenuous 
than those addressing relationships with other dietary factors, because the problems of under-reporting are more severe. Surveys conducted in several different EUcountries quite consistently show that non-drinkers are more likely to be overweight and obese than individuals that drink alcohol. However, there is an important gender difference. Among males there is a slight positive association between alcohol intake and body fatness, while in females a strong inverse relationship is suggested, i.e. that the prevalence of obesity in nondrinkers is 2 times higher than in those with the highest alcohol intake. Neither suppressed intake of other foods, higher levels of physical activity or enhanced thermogenic effect of alcohol seem to explain the apparent reduced body weight of high alcohol consumers. The discrepancy between the law of thermodynamics and the epidemiological findings remains to be reconciled.

In the meantime a conservative view on alcohol should be held: alcohol provides energy which is likely either to displace, or to be additive to, more nutritious foods. Alcohol suppresses fat oxidation, thereby allowing more dietary fat to be stored. The satiating effect of alcohol energy may be low and alcohol consumption has been shown to promote passive over consumption of fat. High alcohol consumption also increases the risk of losing control over otherwise restrained behaviour. Consequently, energy from alcohol should be limited.

\section{Physical activity}

\section{Observational studies on physical activity and body fat gain}

Physical activity is a term used to describe all movement produced by skeletal muscles which increases energy expenditure, whether exercise or sport. At present daily participation in moderate and vigorous physical activities is low, and activity decreases with increasing age. There has been a critical reduction in incidental lifestyle related activity, resulting in reduced energy expenditure and fitness in most populations in the last 30 years. There are now fewer active jobs, greater reliance on motorised transport, sedentary home entertainment, and laboursaving devices at home, at work and in the shopping environment. The small increases in moderate to vigorous leisure time and sports activities are not sufficient to counterbalance this decrease. The development in young people is of particular concern. Numerous cross-sectional and longitudinal studies have shown associations between physical inactivity and obesity ${ }^{40}$. Prentice and $\mathrm{Jebb}^{41}$ have shown that two indicators of inactivity (hours per week of television viewing and number of cars per household) are closely related to the current British secular trend in obesity (Fig. 6). Furthermore, older subjects tend to be more inactive than their younger counterparts and this difference has been suggested to contribute to obesity. It is supported by 10 -year follow-up data on females with a mean age of 46 from the NHANESI study where, at baseline and at follow-up, physical activity was inversely related to body weight. Subjects with a low physical activity level at follow-up were 3.8 times more likely to have gained $>13 \mathrm{~kg}$ during the preceding 10 years. Other prospective studies have found that low levels of physical activity are associated with weight gain and larger increases in waist circumference. Cross-sectional studies have demonstrated that subjects who regularly perform endurance exercise have less body fat and trunk fat than sedentary controls. Both the exercise volume and fitness were inversely related to total fat mass. Some studies have failed to confirm this finding, but in larger cross-sectional studies, with controls for more confounders, intra-abdominal fat measured with computed tomography was inversely related to physical activity. When the quantification of physical activity is improved by measurement of total free living energy expenditure by doubly labeled water technique, reduced physical activity levels are seen to be associated with increased body fat.

In a recent systematic review and meta-analysis of controlled intervention studies, Fogelholm and Kukkonen-Harjula concluded that exercise training only reduced weight gain from 0.33 to $0.28 \mathrm{~kg} /$ month in comparison with a sedentary control group. However, in most of the studies the increase in energy expenditure in physical activity (EEPA) was modest and the compliance uncertain ${ }^{40}$. They concluded that an increase in energy expenditure in sedentary individuals of approximately 6.3-8.4 MJ/week was associated with improved weight maintenance. However, the amount of physical activity necessary to prevent weight gain was not identified. Schoeller et al. measured EEPA by doubly labeled water in previously obese women and found that a PAL (Total EE: RMR) of 1.9-2.1 was the threshold required to exceed for weight maintenance ${ }^{42}$. This corresponds to EEPA of $47 \mathrm{~kJ} / \mathrm{kg} \cdot \mathrm{d}$ (Fig. 7), or $80 \mathrm{~min} /$ $\mathrm{d}$ of moderate physical activity, or $35 \mathrm{~min} / \mathrm{d}$ of vigorous activity added to a sedentary lifestyle ${ }^{42}$. The threshold is probably higher in previously obese subject and in individuals with increased susceptibility to weight gain than in subjects without this predisposition. There is epidemiological evidence to suggest that the risk of obesity increases sharply at a PAL of less than 1.80, which should be taken into consideration when recommending increased physical activity ${ }^{43}$. However, one should be aware of the evidence for an interaction between dietary fat content and physical activity, which suggests that less physical activity is needed for those consuming a low-fat, high-carbohydrate diet (see below).

\section{Intervention studies on obesity and fat distribution}

Uncontrolled studies suggest that endurance training reduces both body fat and abdominal fat, and that strength training may cause a $10 \%$ reduction in intra-abdominal 


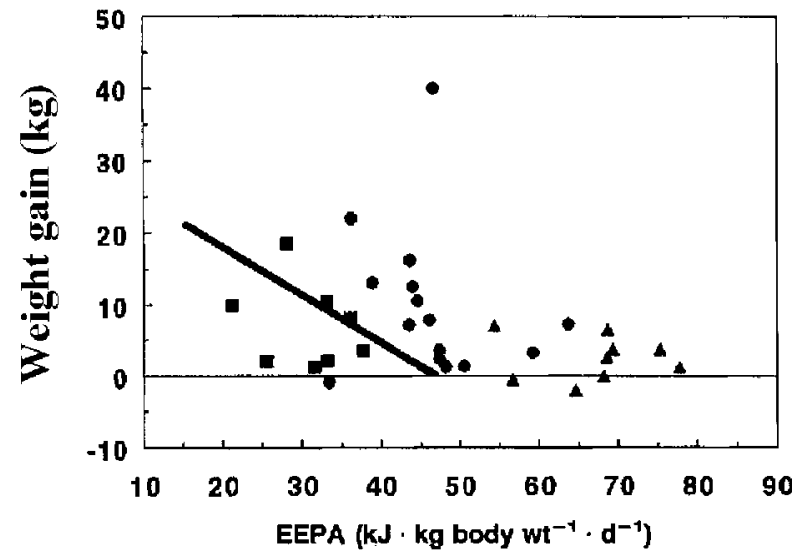

Fig. 7 Relationship between the free living energy expenditure produced by habitual physical activity and subsequent gain of body fat among a group of females with increased susceptibility to weight gain. The intercept with weight gain $=0$ indicates that weight stability requires a daily energy expenditure of at least $47 \mathrm{~kJ} / \mathrm{kg}$ body weight, which corresponds to an average of $80 \mathrm{~min} /$ $\mathrm{d}$ of moderate activity or $35 \mathrm{~min} / \mathrm{d}$ of vigorous activity added to a sedentary lifestyle. (Modified from Schoeller et al. ${ }^{42}$ )

adipose tissue without any notable decrease in body weight or body fat. Studies combining diet and exercise do not allow a separation of the effects of diet and exercise. In a recent report on the treatment of overweight and obesity ${ }^{27}$ the following conclusions were reached: (1) Physical activity contributes to weight loss, both alone and in combination with dietary therapy (evidence category A). (2) Physical activity contributes to a decrease in body fat, including a modest effect on abdominal fat (evidence category B). (3) Physical activity in overweight and obese adults increases cardiovascular fitness independent of weight loss (evidence category A) and (4) Physical activity reduces cardiovascular disease risk factors and reduces the risk of cardiovascular disease (evidence category C).

\section{Conclusions}

Observational cross-sectional and longitudinal studies show that subjects with high levels of physical activity have lower body fat and abdominal fat and are less likely to gain total and abdominal fat than those with low levels of physical activity (evidence category C). Randomised controlled trials comparing exercise with no intervention, and diet with diet plus exercise, are few, but the results available show that increased physical activity prevents or limits the gain of total fat and abdominal fat.

\section{Genetics of obesity}

\section{Genetic susceptibility to obesity}

It is well known that obesity tends to run in families. Current family, twin and adoption studies have provided strong evidence of a genetic influence on body weight and obesity. Estimates have suggested that up to $80 \%$ of the variance in body fatness may be attributed to genetic factors. However, such estimates are potentially misleading because they may give the impression that most obese have been genetically predetermined to their obesity, and that changes in lifestyle factors may have little impact in changing the increase in body weight ${ }^{11}$. However, these estimates are highly dependent on the variation in environmental obesity promoting factors. For instance, in a highly sedentary study population, where almost all subjects are uniformly sedentary, most variance between the subjects in body fatness might be attributed to genetic factors. How does this fit with the observed epidemic of obesity, as it may be assumed that the gene pool has not changed in this period of time? The obesity genes are regarded as susceptibility genes, which are expressed and become functional only when the individual is exposed to a certain set of environmental factors, such as an energy dense diet and a sedentary lifestyle. Currently, monogenetic obesity is extremely rare and the genetic influence on obesity should be regarded rather as a predisposition to body weight gain and obesity due to the presence of alleles on several loci bringing about the increased susceptibility.

Obesity is a classic example of a non-communicable disease of complex multifactorial origin. One characteristic is that it is caused not only by lifestyle and other environmental factors, but also by genetic determinants. There are important individual differences in responses to various lifestyle and environmental exposures, and genetic factors play an important role in modulating this responsiveness. Such genetically mediated sensitivity to environmental exposure is referred to as gene-environment interaction. Food intake and physical activity are examples of environmental factors that influence the risk of obesity and diabetes. A lifestyle characterized by daily physical activity and by the recommended diet is known to reduce the risk of obesity and diabetes. These population based recommendations do not take into account the large individual differences observed in the response to changes in diet and physical activity and assume that everybody responds in a similar manner. However, several studies have shown that there is a considerable heterogeneity in the response in plasma lipids to changes in dietary fat and in the response of the indicators of cardiorespiratory endurance to regular exercise. What is generally considered an obesity promoting and atherogenic diet may in reality pose little risk for some segments of the population. In contrast, what is considered a prudent diet for the majority of the population may have little beneficial effect on a particular segment of that population. The background for this heterogeneity is currently only partly understood but there is considerable evidence, both from studies of twins and from molecular studies, to support that genes play a role in this phenomenon. Genetic variations in several candidate genes have been investigated for their potential role in determining the response to diet change and 
regular physical activity. The majority of these studies have been conducted with dietary fat as exposure factor, and with blood lipids and lipoproteins as risk factor variables, and they have shown that genetic variation in several genes related to lipid metabolism (apolipoproteinapo A-1, apoA-IV, apo CIII etc.) is involved in modulating the response to dietary fat. Appetite, energy intake and energy balance as risk factor variables have not been studied to the same extent, but a large number of candidate genes for obesity and diabetes are currently under investigation ${ }^{44}$.

The research on the obesity genes has brought an increased physiological understanding of the regulation of energy balance and body fat stores, and may be an important tool for more specific and tailor made screening programmes, and for more specific preventive and treatment options in the future.

\section{The leptin system and candidate genes of obesity}

Great progress has been made in the last 10 years in identifying the genes that underlie most rodent models of obesity and in understanding the role that these genes play in the regulation of energy balance ${ }^{45}$. The discovery of the lipostatic hormone leptin and its receptors brought new hope for the imminent discovery of the causes of human obesity. Although impressive progress has been made in understanding the physiology of the leptin system, hopes that variations in this system might explain an important part of the genetics of human obesity have not been fulfilled. Mutations in both the leptin gene and in its central receptor have been shown to cause severe obesity in humans, but these cases are extremely rare. However, treatment with exogenous leptin in a child with congenital leptin deficiency has proven successful ${ }^{46}$. For the most part obese humans appear to have normal leptin and leptin receptor genes. Moreover, plasma leptin concentrations in obese subjects are higher than in normal weight subjects, demonstrating the expected increase in response to an increased fat cell mass. It is likely that the prime role for leptin is the maintenance of a sufficient size of the fat stores for normal growth, development and reproduction, rather than to protect against an excessive enlargement of fat stores. The importance of other candidate genes is discussed later.

\section{Breast-feeding}

There is evidence to support that children who have not received appropriate breast-feeding are at a higher risk of weight gain and of childhood overweight and obesity. The evidence category is only $\mathrm{C}$, because the impact of breast-feeding on the risk of childhood and adult overweight and obesity has been assessed in only a limited number of studies. Three small studies with limited statistical power failed to detect any association, while two larger studies have found indications of a protective effect of breast-feeding. These two studies found the prevalence of obesity substantially lower in breast-fed children than in children who had never been breast-fed. In the largest study, involving 13345 German children, a clear dose-response effect was found for the duration of breast-feeding and prevalence of obesity ${ }^{47}$. The prevalence of obesity was $4.5 \%$ in children who had never been breast-fed, $3.8 \%$ for 2 months of exclusive breast-feeding, $2.3 \%$ for $3-5$ months, $1.7 \%$ for $6-12$ months and $0.8 \%$ for those who were breast-fed for more than 12 months. The apparent protective effect of breast-feeding could not be explained by differences in social class, education, smoking or other lifestyle factors. Overall, these studies suggest that the risk of obesity in children at the time of school entry can be reduced by 30-40\% if they are breastfed for 3-6 months as compared to no breast-feeding. However, these studies are of a purely observational nature and do not allow any conclusion about causality. Breast-feeding is closely related to education, income, social class and other lifestyle factors, which could also have an important influence on childhood obesity, and the causation therefore remains to be substantiated. A number of hypothesis exist to suggest mechanisms linking breast-feeding to weight gain and obesity, but this research is at an early stage. Breast milk contains several bioactive factors not present in formula milk, which could contribute to metabolic programming. Similarly, infant formulas differ from breast milk in macro- and micronutrients composition. For instance, infant formulas have a high protein content, which has been suggested to promote an adipogenic development in children at an early age.

Despite some weaknesses in the evidence linking breast-feeding to obesity (evidence category C), there are several other health benefits of breast-feeding and a possible protective effect against overweight and obesity should be added to the list. Preventing obesity and its complications may turn out to be an important argument in the drive to encourage breast-feeding in European countries.

\section{Interaction between genes, dietary fat and physical activity}

\section{Interactions between genes and fatty acids}

There are many other possibilities in the pathways that regulate food and energy intake, energy expenditure and fat storage. Recent research has, among several genes, focused on the peroxisome proliferator-activated receptor gamma (PPAR- $\gamma$ ) gene. This gene produces two proteins, one of which, PPAR- $\gamma$ is found in adipose tissue, where it plays a key role in the regulation of adipocyte differentiation. Activation of these receptors causes recruitment of preadipocyte fibroblasts to form mature cells, which then accumulate triglycerides. Polymorphisms and mutations in the PPAR- $\gamma$ gene or the encoding region of the gene 
have been associated with obesity and diabetes. The endogenous PPAR- $\gamma$ ligands are fatty acids, eicosanoids and prostglandins, which suggests the possibility that hyperplasia might be induced by factors other than the state of fullness of the existing adipocytes. These might include certain dietary components such as specific fatty acids, for example trans-fatty acids, which have been linked to weight gain in prospective studies. A marked increase has been observed in the ratio of n- 6 to $n-3$ fatty acids in the diets of most EU countries concomitant with the rapid rise in the prevalence of obesity. It is possible that such, so far unrecognized, dietary factors may prove to be significant in the etiology of obesity.

\section{Interaction between genes and dietary fat}

The susceptibility to gain weight on high fat diets is highly genetically determined in rodents. Recently, it has been shown that the Mahogany gene seems to determine the susceptibility of mice to become obese on a high fat $\operatorname{diet}^{44}$. It is likely that the same phenomenon exists in humans, but the role of the Mahogany gene remains to be elucidated. Longitudinal studies have suggested that the development of obesity is promoted by a high fat diet, particularly in subjects with a familial predisposition to obesity, which is probably genetically determined ${ }^{48}$. A low ability to oxidise fat has been proposed as a genetically determined trait which may be expressed phenotypically as a positive fat balance when consuming a high fat diet, which in turn may cause weight gain and obesity $^{14}$. Why does dietary fat only promote passive overconsumption and weight gain in certain susceptible individuals? This question remains to be answered, but ongoing research finds it difficult to dissociate fat's high energy density from biochemical properties related to its metabolism. Altered mechanisms involved in the partitioning and oxidation of fat may be important. Fat oxidation rate is determined by the individual's energy requirement, energy balance, dietary fat content, physical fitness, plasma insulin, estrogen levels and sensitivity, circulating lipid substrates, skeletal muscle uptake, and activity of oxidative enzymes ${ }^{49}$. After controlling for dietary fat intake, energy balance and aerobic capacity, fat oxidation rate has been shown to be a family trait with a heritability of $30 \%$. A low fat oxidation for a given dietary fat content is a risk factor for subsequent weight gain, and is prevalent among formerly obese subjects with a family history of obesity. Strictly controlled metabolic studies have demonstrated that the impaired oxidative capacity of obese and post-obese subjects limits fat oxidation, particularly post-prandially and during exercise. Fat mobilisation through lipolysis is intact but skeletal muscle uptake and oxidation is restricted. Possible responsible mechanisms are: altered responsiveness of thyroid hormones and sympathetic nervous system activity to a high fat diet, high insulin sensitivity, low LPL-activity, and $\beta$-hydroxy-acyl-CoA-dehydrogenase in the muscle fibres. The mechanisms linking low fat oxidation and positive fat balance to the stimulation of appetite and energy intake are poorly understood.

\section{Interactions between genes and physical activity}

Only few important genes have been discovered but a number of likely susceptibility genes have been reported, and they seem to predispose to obesity if a subject possesses both alleles of a mutation or a polymorphism from a couple of different genes of importance for body weight regulation. The interaction with environmental factors may be crucial for their expression. An example is a polymorphism of the beta-2-adrenoceptor gene which, in a Swedish study, was associated with obesity, whereas a Danish study failed to find any association with body weight and weight gain. A recent French study elegantly demonstrated that the presence of the polymorphism did not lead to obesity in physically active subjects, but in those without regular physical activity the genotype was associated with $7 \mathrm{~kg}$ higher body weight (2 BMI units) and a larger waist circumference ${ }^{50}$. This is a nice example of how a physiological system which, in the present case, controls lipolysis (i.e. fat mobilization from the fat stores) may be unaffected be a functional defect in a receptor if compensatory mechanisms are in operation. In this case exercise may have counteracted the defect by increased activation of sympathoadrenal activity and post-receptor sensitization to catecholamines.

\section{Interactions between dietary fat and physical activity}

The prevalence of obesity has, in a number of countries, continued to rise despite a reduction in the proportion of Joules from fat in the national diets. Having been observed in the U.S.A. the phenomenon has been named 'The American Paradox'. Among the explanations suggested for the apparent contradiction have been a concomitant over-riding effect of decreasing physical activity, overconsumption of highly palatable energy dense, carbohydrate rich, low fat products, under-reporting of fat consumed in dietary surveys, and obesity being an infectious disease caused by an adenovirus ${ }^{51}$. It should be stressed, however, that a high dietary fat content is unlikely to be the only environmental factor responsible for obesity. A sedentary lifestyle with a low level of energy expended on physical activities is another causative factor, which interacts with dietary fat content ${ }^{41}$. This is emphasised in the studies by Stubbs et al. where they demonstrated that even in non-obese individuals, dietary fat tolerance is greatly lowered by a sedentary lifestyle $\mathrm{e}^{52,53}$. The result of this short-term study has been extended by a meta-analysis of intervention studies on the effect on weight loss of low fat diets alone and in combination with exercise ${ }^{18}$. Weight loss achieved by low fat diet alone was $2.8 \mathrm{~kg}$, with diet and exercise combined it was $5.7 \mathrm{~kg}$. It should be noted that these studies were in 
non-obese individuals. On a population basis the change of a mean body weight of $5 \mathrm{~kg}$ may produce quite a dramatic change in the prevalence of obesity ${ }^{11}$.

The decrease in physical activity observed in population studies may, therefore, be responsible for the continuing increase in the prevalence of obesity and the very modest, if any, decrease in dietary fat intake is not sufficient to retard this development.

The energy density of foods has been shown to play a major role in the regulation of the spontaneous energy intake, but macronutrient specific properties may also be important in the propensity to major weight gain and obesity. The propensity to gain weight on an energy dense, high fat diet may be enhanced in sedentary individuals ${ }^{54}$. In conclusion, the susceptibility to weight gain is highly dependent on the daily level and pattern of physical activity, and on the presence of obesity susceptibility genes (evidence category B).

\section{Can obesity be prevented?}

Individual differences in the responsiveness to chronic alterations in energy balance induced by an obesity promoting lifestyle appear to be ubiquitous. Variation in many different genes contributes in important ways to the response heterogeneity. The existence of these genenutrient and gene-physical activity interaction effects with a role in obesity and diabetes has considerable public health implications. It implies that, in the future, the potential level of risk of obesity and its comorbidities can be defined for the individual at the molecular level, and that appropriate dietary factors and activity patterns may be designed for the individual. Preventive medicine and public health strategies could be developed for population subgroups with an emphasis on high risk individuals. One can anticipate that major advances will occur in the next decade with identification of more of the genetic and molecular causes of individual susceptibility to obesity and diabetes.

There is evidence to support the effect of the recommendations of health and nutrition education programmes (evidence category B). For example, a school based intervention programme involving 4,171 pupils in the first grade in 2 counties of Crete managed to produce a lower increase in BMI and beneficial changes in blood lipids than in a control group over a 3 year period $^{55}$.

Preventive efforts should take into consideration that the prevention of obesity is complex, involving physiological, economic and social factors, and may interfere with competing interests. A working group under The International Obesity Task Force has developed an integrated framework to illustrate the societal influences on obesity prevalence (Fig. 8) ( $^{56}$.

The diagram shows the factors that operate at similar social structural levels labeled across the top. The most common target for interventions to reduce obesity levels is individual behaviour (shown to the right). The large number of arrows indicate the factors bearing on individual behaviour, which challenges the notion of individual 'free will' regarding food choice and energy expenditure.

The School/Work/Home column represents the next most common focus for intervention. Each of these sites is influenced by factors further upstream. For example, although schools can be a target for changing the food supply or physical activity patterns of youth, they rarely operate independently of external bodies: funding sources, accrediting bodies, and elected school boards all have different agendas for school function and budgeting. The bottom line for schools is academic performance, and health issues are generally secondary.

National policies providing adequate incentives or financial support may be necessary to bring about widespread change in schools - no matter how good a particular educational programme may be. Even the provision of food within the schools encounters linkages with government food policies supporting school lunches, availability of fresh foods, and economic issues linked to the common situation that revenues from food sales and fundraising parents are the only discretionary funds available to schools.

Another example is found in urban planning. The use of stairs instead of elevators is often recommended for people who want to increase physical activity. To support this approach, efforts have been made to work with building designers to make stairs more attractive and convenient, and elevators less so. These efforts have run into myriad problems, including building codes, fire safety standards, design expectations, and architectural prerogative. Even simple solutions become complex.

State and national level policies are linked to international markets and the level of economic development of countries. International monetary agencies and banks may encourage/require debtor countries to use more of their agricultural capacity for export rather than local food supplies, shifting food availability and cost. The activities of international corporations greatly influence food availability and demand through advertising and other marketing; the foods most widely and intensively marketed are likely to have a long shelf life, a very high profit margin, and be easily transported around the globe. International corporations similarly influence purchasing capacity through salaries, and energy expenditure through the level of labour required to earn income.

In this web there is no single organisational locus where motivation to change behaviour can result in a decline in obesity without interference from competing interests. Coalitions with commitment to change must be formed across all levels, founded on mutual interest. This is the classic situation that requires a broad-based public health perspective ${ }^{56}$. 


\section{Societal policies and processes influencing the population prevalence of obesity}

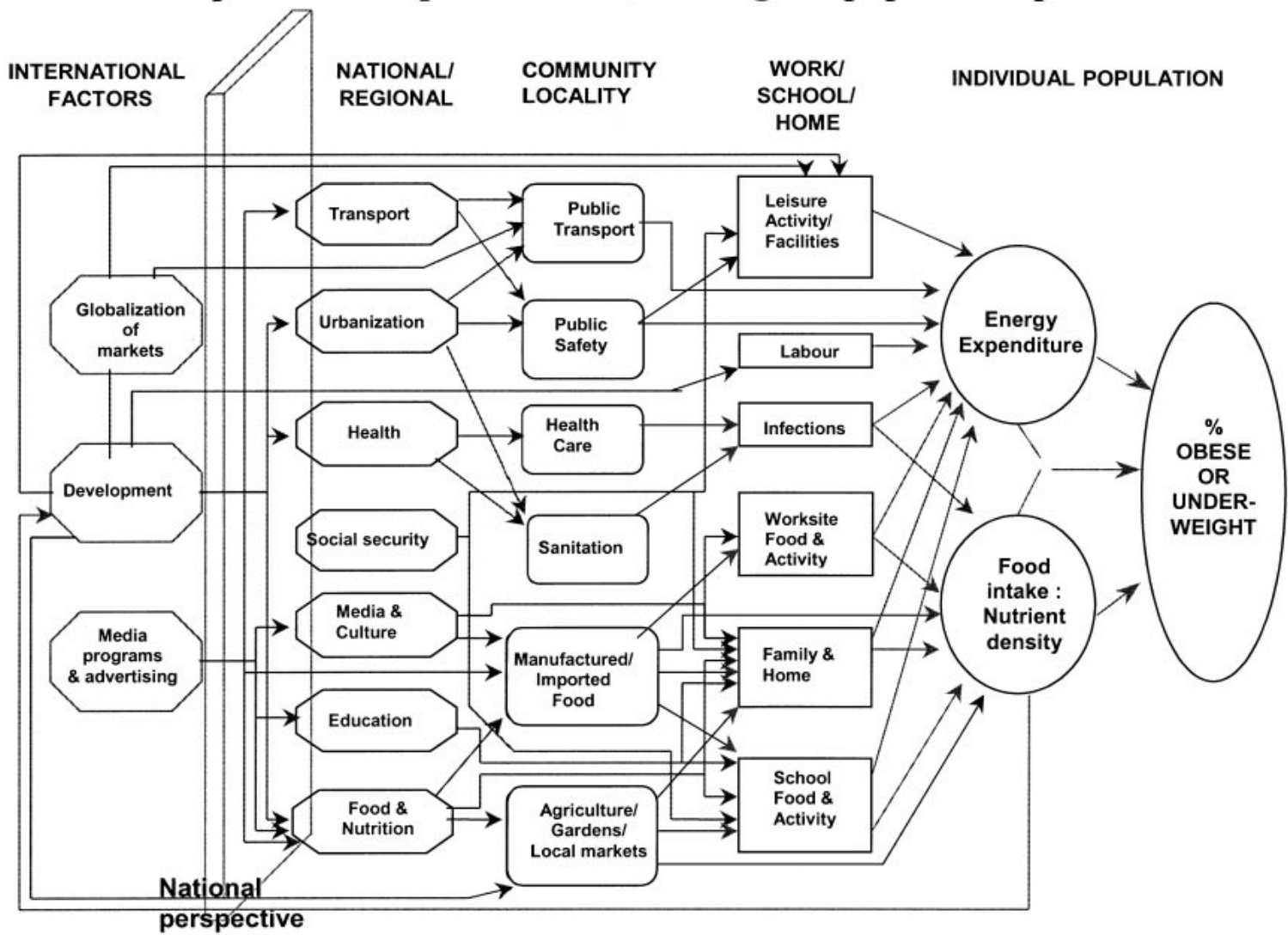

Fig. 8 The 'Causal Web of societal influences on obesity prevalence'. The rectangle after the first column signifies the 'cultural filter' representing influences varying from traditional customs and practices to media and advertising ${ }^{56}$

\section{References}

1 Obesity: preventing and managing the global epidemic. Report of a WHO Consultation on Obesity, Geneva 3-5 June 1997. Geneva: WHO Publications, 1997.

2 Prevention of diabetes mellitus. Report of a WHO study group. WHO Technical Report Series, No. 844, 1994.

3 Astrup A, Finer N. Redefining type 2 diabetes: 'Diabesity' or 'Obesity Dependent Diabetes Mellitus'? Obes. Rev. 2000; in press.

4 Colditz GA, Willett WC, Rotnitzky A, Manson JAE. Weight gain as a risk factor for clinical diabetes mellitus in women. Ann. Intern. Med. 1995; 122: 481-6.

5 Sjöström CD, Lissner L, Wedel H, Sjöström L. Reduction of incidence in diabetes, herpertension and lipid disturbances after intentional weight loss induced by bariatric surgery: the SOS intervention study. Obes. Res. 1999; 7: 477-84.

6 Sjöström L. Obesity, diabetes and other cardiovascular risk factors. Lessons from SOS. Int. J. Obes. 2000; 24(Suppl. 1): S7 (Abs 14).

7 Heymsfield SB, Segal KR, Hauptman J, Lucas CP, Boldrin MN, Rissanen A, Wilding JPH, Sjöström L. Effect of weight loss with Orlistat on glucose tolerance and progression to type 2 diabetes in obese adults. Arch. Intern. Med. 2000; 160: 1321-6.

8 Williamson DF, Pamuk E, Thun M, Flanders D, Byers T, Health C. Prospective study of intentional weight loss and mortality in never-smoking overweight US white women aged 40-64. Am. J. Epidemiol. 1995; 141: 1128-41.
9 King H, Aubert RE, Herman WH. Global burden of diabetes 1995-2025. Diabetes Care 1998; 21: 1414-1431.

10 Astrup A. Macronutrient balances and obesity: the role of diet and physical activity. Pub. Health Nutr. 1999; 2: 341-7.

11 James WPT, Ralph A. Implementing dietary change: theory and practice. Obesity. New understanding in obesity research. Proc. Nutr. Soc. 1999; 58: 385-93.

12 Blundell JE, Cooling J. Routes to obesity: phenotypes, food choices and activity. Br. J. Nutr. 2000; 83: S33-8.

13 Bray GA, Popkin BM. Dietary fat intake does affect obesity. Am. J. Clin. Nutr. 1998; 68: 1157-73.

14 Astrup A, Ryan L, Grunwald G, Storgaard M, Saris W, Hill JO. Ad libitum low-fat diets and body fatness: A meta-analysis of intervention studies. Br. J. Nutr. 2000; 83(suppl 1): S25-32.

15 Goris AHC, Westerterp-Plantenga MS, Westerterp KR. Undereating and underrecording of habitual food intake in obese men: selective underreporting of fat intake. Am.J. Clin. Nutr. 2000; 71: 130-4.

16 Harnack LJ, Jeffrey RW, Boutelle KN. Temporal trends in energy intake in the United States: an ecological perspective. Am. J. Clin. Nutri. 2000; 71: 1478-84.

17 Willet WC. Is dietary fat a major determinant of body fat? $\mathrm{Am}$. J. Clin. Nutr. 1998; 67: 556S-62S

18 Yu-Poth S, Zhao G, Etherton T, Naglak M, Jonnalagadda S, Kris-Etherton PM. Effects of the national cholesterol education program's step I and step II dietary intervention programs on cardiovascular disease risk factors: a metaanalysis. Am. J. Clin. Nutr. 1999; 69: 632-46.

19 Food and Agricultural Organization of the United Nations. Get the best from your food. 1992. 
20 Ludwig DS, Majzoub JA, Al-Zahrani A, Dallal GE, Blanco I, Roberts SB. High glycemic index foods, overeating, and obesity. Pediatrics 1999; 103: 26.

21 Bolton-Smith C, Woodward M. Dietary composition and fat to sugar ratios in relation to obesity. Int. J. Obes. 1994; 18 820-8.

22 Raben A, Macdonald I, Astrup A. Replacement of dietary fat by sucrose or starch: Effects on 14 days' ad libitum energy intake, energy expenditure and body weight in formerly obese and neverobese subjects. Int. J. Obes. 1997; 21: 846-59.

23 Saris WHM, Astrup A, Prentice AM, Zunft FHJ, Formiguera X, Verboeket-van de Venne WPHG, Raben A, Poppitt SD, Seppelt B, Johnston S, Vasilaras TH, Keogh G. Randomised controlled trial on changes in dietary carbohydrate/fat ratio and simple vs. complex carbohydrates on body weight and blood lipids: the CARMEN study. Int. J. Obes. 2000; in press.

24 Salmeron J, Manson JE, Stampfer MJ, Colditz GA, Wing AL, Willett WC. Dietary fiber, glycemic load, and risk of noninsulin -dependent diabetes mellitus in women. JAMA 1997; 277: $472-7$.

25 Salmeron J, Ascherio A, Rimm EB, et al. Dietary fiber, glycemic load, and risk of NIDDM in men. Diabetes Care 1997; 20: 545-50.

26 Schaefer EJ, Lichtenstein AH, Lamon-Fava S, McNamara JR, Schaefer MM, Rasmussen $\mathrm{H}$, et al. Body weight and lowdensity lipoprotein cholesterol changes after consumption of a low-fat ad libitum diet. JAMA 1995; 274: 1450-5.

27 Clinical Guidelines on the identification, evaluation, and treatment of overweight and obesity in adults - The Evidence Report. Obes. Res. 1998; 6(suppl.2): 51S-210S.

28 Frost G, Leeds AA, Doré CJ, Madeiros S, Brading S, Dornhorst A. Glycaemic index as a determinant of serum HDLcholesterol concentration. Lancet 1999; 353: 1045-8.

29 Nordiska Ministerråd. Nordiska näringsrekommendationer 1996. Copenhagen, 1996.

30 Panel on Dietary Reference Values of the Committee on Medical Aspects of Food Policy, The Department of Health. Dietary reference values for food energy and nutrients for the United Kingdom. HMSO, London, 1991.

$31 \mathrm{Ha}$ TKK, Lean MEJ. Recommendations for the nutritional management of patients with diabetes mellitus. Eur. J. Clin. Nutr. 1998; 52: 467-81.

32 Roland-Cachera MF, Deheeger M. Nutrient balance and android body fat distribution: why not a role for protein? Am. J. Clin. Nutr. 1996; 61: S960-7.

33 Skov AR, Toubro S, Rønn B, Holm L, Astrup A. Randomized trial on protein versus carbohydrate in ad libitum fat reduced diet for the treatment of obesity. Int. J. Obes. 1999; 23: 52836.

34 Hill MJ. Meat and colo-rectal cancer. Proc. Nutr. Soc. 1999; 58: $261-4$

35 Bingham SA. High-meat diets and cancer risk. Proc. Nutr. Soc. 1999 ; 58 : 243-8.

36 Dulloo AG, Mensi N, Seydoux J, Girardier L. Differential effects of high-fat diets varying in fatty acid composition on the efficiency of lean and fat tissue deposition during weight recovery after low food intake. Metabolism 1995; 44: 273-9.

37 Doucet E, Ameréras N, White MD, Després J-P, Bouchard C, Tremblay A. Dietary fat composition and human adiposity. Eur. J. Clin. Nutr. 1998; 52: 2-6.

38 Lawton CL, Delary HJ, Brockman J, Smith FC, Blundell JE.
The degree of saturation of fatty acids influences postingestive satiety. Br. J. Nutr. 2000; 83: 473-82.

39 Prentice AM. Alcohol and obesity. Int. J. Obes. 1995; 19(suppl. 5): S44-50.

40 Fogelholm M, Kukkonen-Harjula K. Does physical activity prevent weight gain - a systematic review. Obes. Rev. 2000; in press.

41 Prentice AM, Jebb SA. Obesity in Britain: Gluttony or sloth? Br. Med.J. 1995; 311: 437-9.

42 Schoeller DA, Shay K, Kushner RF. How much physical activity is needed to minimize weight gain in previously obese women? Am. J. Clin. Nutr. 1997; 66: 551-6.

43 Ferro-Luzzi A, Martino L. Obesity and physical activity. The origins and consequences of obesity, CIBA Foundation Symposium 201. Chichester: John Wiley \& Sons, 1996.

44 Nagle DL, McGrail SH, Vitale J, Woolf EA, Dussault BJ, DiRocco L, et al. The mahogany protein is a receptor involved in suppression of obesity. Nature 1999; 398: 148-52.

45 Zhang Y, Proenca R, Maffei M, Barone M, Leopold L, Friedman JM. Positional cloning of the obese mouse gene and its human homologue. Nature 1994; 372: 425-32.

46 Farooqi IS, Jebb SA, Langmark G, Lawrence E, Cheetham CH, Prentice AM, Hughes IA, McCamish MA, O'Rahilly S. Effects of reombinant leptin therapy in a child with congenital leptin deficiency. N. Engl. J. Med. 1999; 341(12): 879-84.

47 Von Kries R, Koletzko B, Sauerwald T, von Mutius E, Barnert D, Grunert V, von Voss H. Breast feeding and obesity: cross sectional study. Brit. Med. J. 1999; 319: 147-50.

48 Meirhaeghe A, Helbecque N, Cottel D, Amouyel P. $\beta_{2^{-}}$ adrenoceptor gene polymorphism, body weight and physical activity. Lancet 1999; 353: 896.

49 Astrup A, Flatt JP. Metabolic determinants of body weight regulation. In: Bouchard C, Bray GA, eds. Regulation of Body Weight, Biological and Behavioral Mechanisms - Dahlem Workshop. Report LS 57. Chichester: John Wiley \& Sons, pp. 193-210, 1996.

50 Astrup A, Raben A, Buemann B, Toubro S. Fat metabolism in the predisposition to obesity. Ann. NY. Acad. Sci. 1997; 827: 427-33.

51 Astrup A, Lundsgaard C, Stock MJ. Is obesity contagious? Int. J. Obes. 1998; 22: 375-6.

52 Stubbs RJ, Harbron CG, Murgatroyd PR, Prentice AM. Covert manipulation of dietary fat and energy density: effect on substrate flux and food intake in men eating ad libitum. $\mathrm{Am}$. J. Clin. Nutr. 1995; 62: 316-29.

53 Stubbs RJ, Ritz P, Coward WA, Prentice AM. Covert manipulation of the dietary fat to carbohydrate ratio and energy density: effect on food intake and energy balance in free-living men, feeding ad libitum. Am. J. Clin. Nutr. 1995; 62: $330-7$.

54 Lissner L, Heitmann BL, Bengtsson C. Low-fat diets may prevent weight gain in sedentary women: Prospective observations from the population study of women in Gothenburg, Sweden. Obes. Res. 1997; 5(1): 43-8.

55 Manios Y, Moschandreas J, Hatzis C, Kafatos A. Evaluation of a health and nutrition education program in primary school children of Crete over a three-year period. Prev. Med. 1999; 28: $149-59$.

56 Kumanyika S, Jeffery R, Ritenbaugh C, Morabia A, Antipatis V. Causal Web of Societal influences on obesity prevalence. www.iotf.org/groups/phapo (1999). 